\title{
Arte e educação: o espaço urbano como eixo da experiência estética
}

\author{
Carlos Weiner M. de Souza (ECA-USP)
}

\section{Resumo}

Os espaços vividos, as visualidades e não-visualidades construídas por meio da mobilidade no espaço urbano e do cotidiano são uma constante nas relações conflitantes entre identidades e valores culturais. Neste artigo abordamos essa dinâmica tomando como ponto de partida as relações entre estética e política, cidade e comunidade, tomando como referência empírica a experiência com estudantes, moradores de um bairro de periferia da cidade de Paranaguá/PR.

Palavras Chave: Arte; educação; estética; política.

\section{Introdução}

\footnotetext{
"A arte é um elemento fundamental para que, expressando suas vivências, o educando possa chegar a compreendê-la e a emprestar significados à sua condição no contexto cultural". (DUARTE JÚNIOR, 2010, p.134).
}

No ano de 2008, iniciamos um projeto educacional em arte com 25 crianças e adolescentes, na região periférica da cidade de Paranaguá, litoral do Paraná, que se estendeu até o ano de $2010^{i}$. Na execução da proposta, vinculada às ações de extensão realizadas pela Universidade Federal do Paraná (UFPR), estabelecemos desde o princípio a preocupação com os aspectos culturais e espaciais nos quais estavam inseridos os participantes do projeto.

O ponto de partida para a experiência artística, com base na linguagem fotográfica, eram os espaços vividos, as visualidades e não-visualidades construídas por meio da mobilidade no espaço urbano, do cotidiano e as constantes tensões entre identidades e valores culturais que brotam dessa relação.

Refletir acerca do lugar que as imagens ocupam em nosso cotidiano e sobre as maneiras como nos postamos em relação a elas, se tornou uma das questões centrais nas investigações da educação em arte. Tomando como horizonte as práticas educativas que se inserem no entrecruzamento entre a subjetivação, o entendimento estético e a alteridade, pensamos as 
visualidades e as não-visualidades como um processo mediado estética, cultural e socialmente, como um elemento central na construção das identidades que podem se articular ao processo educativo e mobilizar o sentimento participativo para a vida social.

Nesse contexto, o espaço emergiu como um fundamento de nosso trabalho educativo, como um elemento agregador das paisagens subjetivas e motivador dos desejos de configurar formas artísticas. A cidade nos conduziu em busca de significados e de elaboração/reelaboração da vivência educativa. Identidade, memória e valores em relação à ela tornaram-se possibilidades para a configuração de alteridades.

Tomamos de empréstimo os argumentos de Jacques Rancière (2010) de que a estética deve ser entendida como a partilha do sensível, e de que toda arte é política, por lidar com o que é visível e invisível (FIALHO, KUNSCH, 2010). Nessa perspectiva, e, transportando a responsabilidade que o autor atribui ao artista, também ao educador em arte, consideramos incorporar às práticas educacionais a investigação de "um determinado aspecto da realidade que está enquadrado, esteriotipado ou formatado no senso comum" (FREITAS, 2012, s. p.). Esse modelo é importante não como uma pedagogia, mas como uma reconfiguração do mundo sensível.

Trata-se de definir a relação entre uma ordenação social dos modos de visibilidade, de fazer e de dizer, e colocar em pauta uma outra dimensão, a estética. Essa dimensão da experiência humana pode inaugurar novos modos de ver e sentir, e, portanto, se constitui como uma dimensão política. Uma espécie de forma a priori da subjetividade que afeta a distribuição inquieta de lugares e ocupações e dinamiza os modos negociados de visibilidade que "faz ver quem pode tomar parte no comum em função daquilo que faz, do tempo e do espaço em que essa atividade se exerce" (RANCIÈRE, 2005, p. 16).

Assim, podemos pensar nessas relações, em termos de educação no campo das artes, como formas de operar, de articular ações e estimular maneiras de fazer que "intervêm nas relações com as maneiras de ser e formas de visibilidades", do qual derivam, ao mesmo tempo, um "comum partilhado e partes exclusivas" configuradas em formas artísticas (Idem, 2005, p.15-17).

Destarte, estabelecemos o recorte para tratar da experiência e refletir sobre as imagens do projeto a partir da relação entre o que foi produzido pelos estudantes e os desdobramentos obtidos por meio da transformação e circulação dessas imagens, tanto no contexto 
educacional, quanto da própria cidade. Trata-se de apresentar em que sentido tais imagens se articulam politicamente, em sua circulação estética-social-cultural, e, neste movimento aportam elementos para refletirmos sobre o processo educacional.

\section{As cidades em uma mesma cidade}

As figuras de 01 a 04 destacam as dimensões do processo que foram experienciadas e deram forma ao trabalho final do projeto. A primeira (figura 01) refere-se aos estudos sobre a cidade, à pesquisa iconográfica das imagens históricas da cidade, junto ao Instituto Histórico Geográfico da cidade de Paranaguá. Estas datavam de 1897 a 1960, e formavam um composto histórico que dava ênfase ao cotidiano da cidade, às transformações arquitetônicas e espaciais, às festas populares e religiosas e aos costumes locais. A segunda (figura 02) faz referência à produção fotográfica dos estudantes em sua incursão pela cidade, no encontro com as "rugosidades" (SANTOS, 2012), heranças temporais no espaço ${ }^{\mathrm{ii}}$ e os sentimentos contraditórios que despertam.

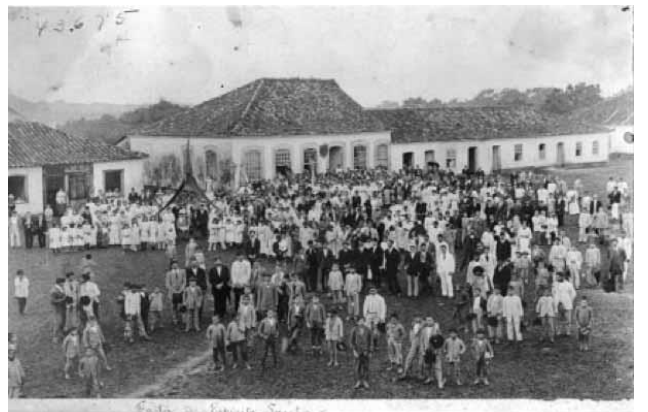

Figura 01. Fotografia. Festa do Espírito Santo, 1898.

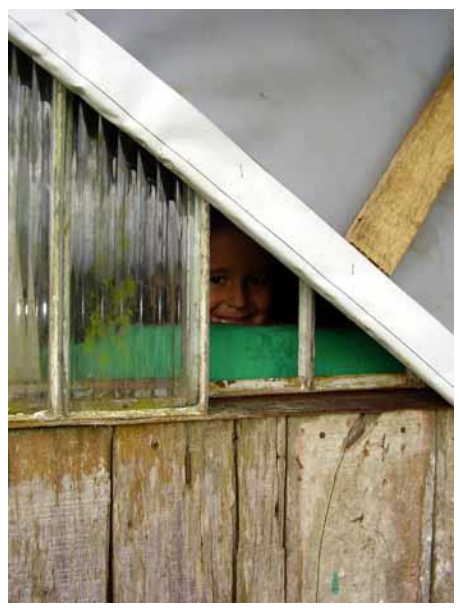

Figura 03. Fotografia. A casa. Cristofer Luiz. Acervo Projeto Vila, 2008.

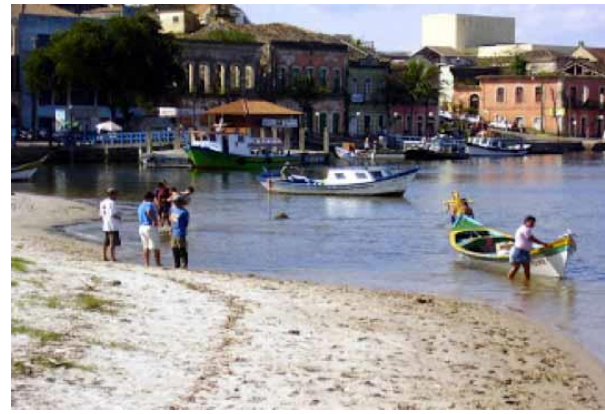

Figura 02. Fotografia. Centro Histórico de Paranaguá. Juliane Fernandes. Fonte: Acervo Projeto Vila, 2008.

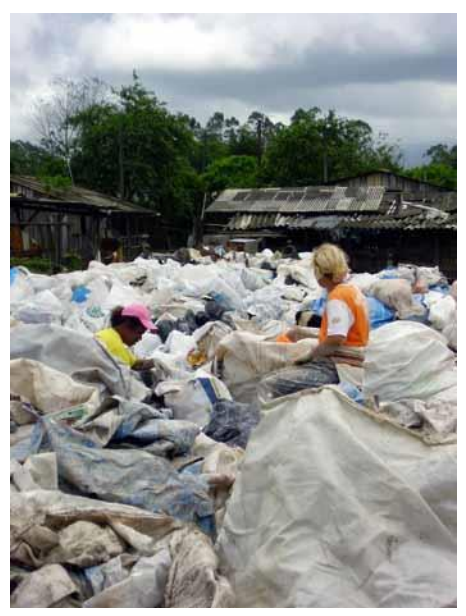

Figura 04. Fotografia. Associação de Separadores. Alessandra Dias. Acervo Projeto Vila, 2008. 
Dietzasch (2006) afirma que

[...] no suceder contraditório de tempos, marcas e marcos, é possível que se vislumbrem não apenas o homem com suas memórias, sonhos e força criadora, mas também com seus vícios, seus medos e desesperanças (p. 731).

Dessas relações nasce a terceira dimensão do processo: um derivado da percepção e interrelação oferecida pelas paisagens, pela vivência dos conjuntos arquitetônicos históricos, praças, vias públicas da cidade, em sua tangência com os espaços domésticos dos estudantes (Figuras 03 e 04).

A política da arte não está em tecer explicações do mundo e sim laços comunitários. As imagens produzidas pelos estudantes no interior da vila onde residem, ao mesmo tempo em que nos apresentam uma referência autobiográfica, um sentido comunitário, nos mostram o seu afastamento e exclusão da dinâmica da cidade. Observou-se uma invisibilidade da cidade para o grupo envolvido na experiência, assim como evidencia-se a invisibilidade do espaço por eles habitado.

O contato com os monumentos e espaços que fazem parte da história oficial da cidade, as igrejas, museus, prédios da administração pública evidenciou o distanciamento que os estudantes da Vila Santa Maria tinham dela. Mesmo as ruínas da cidade — Paranaguá tem muitas delas em função do descaso com o patrimônio histórico — não despertaram, a princípio, interesse efetivo. Ratifica-se qe os objetos do passado, a noção de patrimônio, os signos da cultura não são comuns a todos os indivíduos.

Na diversidade é que se tornam significativos e podem assumir mais ou menos relevância para construção da identidade cultural dos sujeitos. (SMOLKA, 2000, p. 48).

No entanto, o processo educacional que promove a experiência com estes signos, pode romper as barreiras que impedem não a significação diversa, que é imprescindível para mobilidade social, mas a inacessibilidade que sustenta a exclusão estética.

\section{Compartilhando as imagens, multiplicando os saberes}


A arte não é política pelas mensagens e os sentimentos que transmite acerca da ordem do mundo. Nem pela maneira como representa as estruturas da sociedade, os conflitos ou as identidades dos grupos sociais. É política pela mesma distância que adota a respeito de suas funções, pela espécie de tempo e de espaço que institui, pela maneira que recorta este tempo e povoa esse espaço (RANCIÈRE, 2010, p.20).

A maneira pela qual o projeto foi estruturado e se desenvolveu permitiu que viajássemos nos tempos da cidade, e, pelo ato de fotografar, descobríssemos sentidos nos tempos subjetivos. Aprendemos, recordamos, provocamos o olhar sobre as realidades da cidade e, sobretudo, a percepção, a ação criativa ${ }^{\text {iii }}$ e o desejo de autoria. Aqui não nos referimos apenas à autoria artística, apesar das imagens apontarem para esse aspecto, mas, sobretudo, autoria como autodeterminação, que é o que nutre a busca por sentidos individuais e coletivos para as coisas do mundo e nos dá autonomia para nos posicionarmos e nos expressarmos diante delas.

Assim, faz-se necessário resgatar um dos elementos centrais do processo pedagógico. O fato de que aprender e apreender as coisas do mundo só assume significado pela criação de um mundo, que, antes de ser real, é pessoal. Antes da incursão no contexto da cidade trabalhamos com as imagens que compõem o microcosmo de cada casa, trouxemos para a prática pedagógica as imagens presentes no cotidiano dos estudantes.

Neste contexto, levamos ao contato com o fazer artístico por meio daquilo que suas mãos podem alcançar, o que está esquecido no armário, no canto do quarto, no fundo do quintal. Iniciamos um processo de aprendizagem, despertando, pelo fazer, antes do dizer ou do mostrar, a vontade de criar mundos que possam estabelecer diálogos entre a intencionalidade e os elementos que compõem a linguagem plástica e visual.

O importante nesse procedimento era que os estudantes, ao manusearem a máquina fotográfica, encontrassem nessa relação entre objetividade e subjetividade, a materialidade do meio e a imaterialidade expressa na vontade de dar forma. Isto porque tais elementos estão implícitos no fazer artístico. $\mathrm{O}$ ato de fotografar, além de mobilizar o corpo, instiga o sujeito a pensar sobre como ele se apresenta em diversas situações, abre as portas para os significados que nossa subjetividade adquire no cotidiano.

Nesse sentido, o recorte do mundo visível e invisível, proporcionado pela fotografia, criou condições para que os estudantes pudessem habitar as imagens, descobrir a importância 
dos detalhes e mergulhar na relação em que sujeito e objeto se disponibilizam ao diálogo. Como base nessa ideia, é que decidimos estruturar a exposição final do projeto, unindo a pesquisa sobre as imagens da cidade e o material produzido pelos estudantes. Dessa maneira, destacar a ressonância de várias vozes, do micro ao macro, que se encontram nas imagens/tempos/espaços que compõem a cidade.

Rancière (2012b) aponta para a construção de imagens que podem contribuir de forma sutil para desenhar novas formas de articulação entre o dizível, o visível e o pensável. Dessa forma, consideramos que ao definir uma unidade, dar forma para o conjunto das imagens e, por conseguinte, colocá-las em trânsito, não apenas em forma de exposição, mas de material pedagógico nas escolas públicas da cidade (figuras de 05 a 08), realizamos uma opção por agregar esteticamente essas múltiplas percepções relacionadas à dinâmica da cidade.

Pensamos, nesse sentido, nas próprias composições imagéticas e nas possibilidades de significação a elas associadas, como instrumentos ativadores de alteridades e políti-cidades da arte.

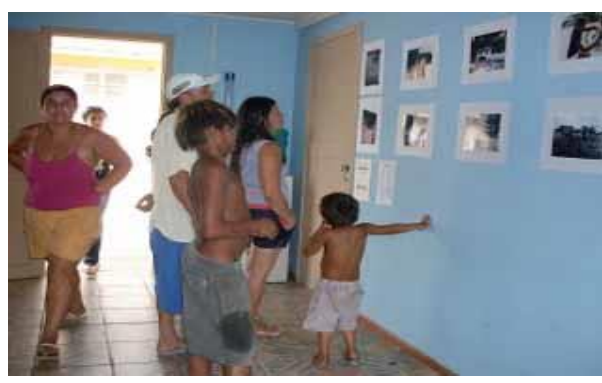

Figura 05. Fotografia. Exposição na Vila Santa Maria. Carlos Weiner. Acervo Projeto Vila,

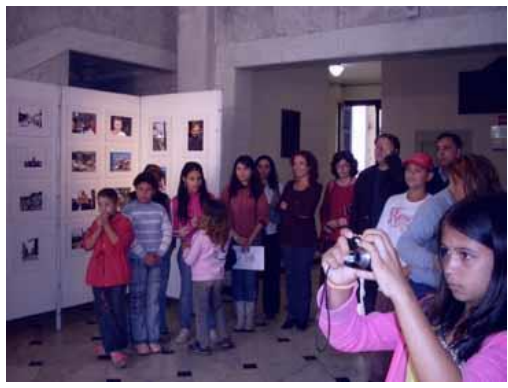

Figura $07 . \quad$ Fotografia. Exposição no Museu de Arte da Universidade Federal do Paraná - Curitiba-PR. Alessandra Dias.

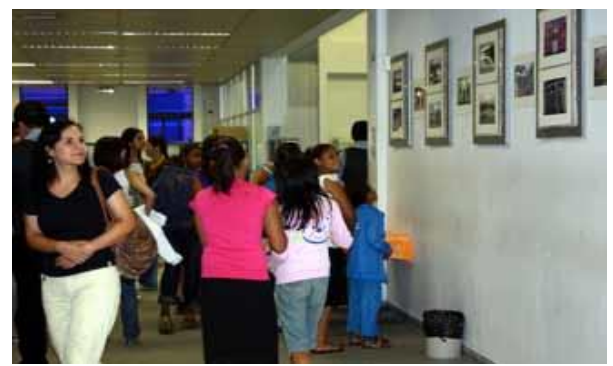

Figura 06. Fotografia. Exposição na Caixa Econômica Federal. Carlos Weiner. Acervo Projeto Vila, 2009.

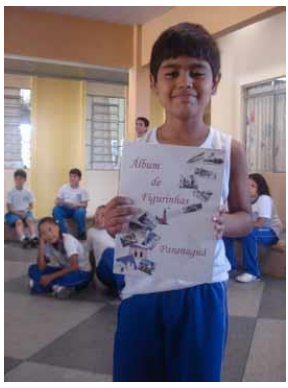

Figura 08. Fotografia. Estudantes da Escola Municipal Nascimento Junior. Álbum de figurinhas com as imagens do projeto. Janelize Nascimento. Acervo Projeto Vila, 2009. 
servamos que, por meio das ações educativas, o tratamento da relação sujeito-imagem-cidade não apenas em sua visualidade, mas pelo que nelas opera, o não-visível, o que se articula nos registros entre a realidade que circunda os espaços domésticos, de afetividade e a dimensão prática da existência do lugar. Procuramos assinalar os conflitos de formas, temporalidades e espaços com o propósito de desobstruir o olhar e perceber as diferenças, transformar as aparências em novas formas de percepção.

Por meio dessa articulação e mobilização do campo estético, tornam-se incontáveis as formas e valores simbólicos que podem fluir do contato visual dos estudantes com a cidade. De outra forma estaríamos no consenso de ações educacionais em arte que, frequentemente, terminam por consolidar a verticalidade, a hierarquia de um domínio ideológico que nos faz crer que a imagem deve ser reduzida à sua visualidade, ao invés de ser compreendida em sua alteridade e conflituosidade características da vida humana em sociedade.

\section{Considerações finais}

Em uma tentativa de apontar os elementos que nos marcaram mais profundamente na vivência e na reflexão sobre a experiência, podemos dizer que, de fato, a apropriação da cidade, do espaço como um fundamento cultural, (SANTOS, 1998) para a realização das práticas pedagógicas é capaz de espelhar a intimidade do mundo subjetivo em sua tangência com o macro e o microcosmo social.

Pelo processo educativo em arte criamos condições para estabelecer os vínculos necessários para atingir os sujeitos por meio das formas plásticas e, assim, acentuar sua potência transformativa na realidade. Trata-se de superar, em consonância com os estudantes, o visível que se nos apresenta como sensações primeiras de uma realidade sem encantamento, combinando sentidos e recordações, afetos e desejos na criação e modos de circulação das próprias imagens.

Acreditamos que para os estudantes foi possível perceber que, "para muito além de um mapa, a cidade tem o sentido de uma rede a permitir o traçado de múltiplos fios que se emaranham em vozes e significações [...] que pode oferecer suas imagens e sentimentos" Dietzsch (2006, p.728).

Consideramos ter iniciado, coletivamente, um processo que pode estabelecer um contraponto à profusão "de imagens [...] que em grande parte são destituídas da necessidade 
interna que deveria caracterizar toda imagem, como forma de significado, como força de impor-se à atenção, com riqueza de significados possíveis" (Calvino, 1990 p.73), e dar um sentido estético e político à nossa existência na cidade.

Notas

i O Projeto Vila Educação e Arte e foi implementado por meio da Incubadora Tecnológica de Cooperativas Populares da Universidade Federal do Paraná (ITCP), hoje, Incubadora de Projetos Econômicos, Sociais e Solidários (IPESS). O projeto se estendeu por dois anos. A primeira etapa o trabalho envolveu um grupo de 25 crianças, com idade entre 10 e 14 anos, filhos de trabalhadores que sobrevivem da coleta e reciclagem do lixo. Em uma segunda etapa, outra comunidade da mesma cidade, pudemos trabalhar tambm com o ambiente escolar e suas particularidades. O trabalho teve sua continuidade com crianças, com idade entre 10 e 12 anos, estudantes rede pública de ensino, gerando um vídeo documentário sobre os Mestres do Fandango da Ilha dos Valadares da cidade de Paranaguá. O referido trabalho que retornou às escolas em forma de material pedagógico.

ii "Chamemos de rugosidade ao que fica do passado como forma, espaço construído, paisagem, o que resta do processo de supressão, acumulação, superposição, com queas coisas se substituem e acumulam em todos os lugares. As rugosidadesse apresentam como formas isoladas ou como arranjos" (SANTOS, 2006:, p. 92).

iii Rancière ao tratar da imagem cinematográfica nos apresenta o conceito de criação com o qual trabalhamos neste artigo. “... não é a criação de um mundo imaginário oposto ao mundo real. É o trabalho que realiza "dissensos", que muda os modos de apresentação do sensível e as formas de enunciação, mudando quadros, escalas ou ritmos, construindo relações novas entre a aparência e a realidade, o singular e o comum, o visível e a sua significação. Esse trabalho muda as coordenadas do representável; muda nossa percepção dos acontecimentos sensíveis, nossa maneira de relacioná-los com os sujeitos, o modo como nosso mundo é povoado de acontecimentos e figuras". (RANCIÈRE, 2012 (a): 64-65

\begin{abstract}
The experienced spaces, visual arts and non-visualities built through mobility in urban space and everyday life are a constant in conflicting relationships between identities and cultural values. In this article we address this dynamic by taking as a starting point the relationship between aesthetics and politics, city and community, taking as empirical reference the experience with students, residents of a difficult neighborhood in the city of Paranaguá / PR.
\end{abstract}

\title{
Referências
}

CALVINO, Ítalo. As cidades invisíveis. Trad. Diogo Mainardi. São Paulo: Companhia das Letras, 1990.

DIETZASCH, Mary Julia Marts. "Leituras da cidade e educação". In: Cadernos

de Pesquisa, v.36, n.129, p. 727-759, set-dez, 2006.

\section{DUARTE JÚNIOR, João-Francisco. A montanha e o videogame: escritos}

Sobre educação. Campinas, SP: Papirus, 2010.

FREITAS, Guilherme, In: Entrevista com Jacques Rancière, "Formas de Vida". Disponível em http://oglobo.globo.com/blogs/prosa/posts/2012/12/08/formas-de-vidajacques-ranciere-fala-sobre-estetica-politica-478094.asp. Acessado em 05/03/2014. 
FIALHO, Ana Letícia e KUNSCH, Graziela. Política da estética: entrevista com Simon Sheikh. $\quad$ In: $\quad$ Revista Trópico, $2010 . \quad$ Disponível $\quad$ em http://p.php.uol.com.br/tropico/html/textos/3217,2.shl .

RANCIÈRE, Jacques. A partilha do sensível, estética e política. São Paulo, Ed. 34, 2005.

Estética e Política. A Partilha do Sensível, com entrevista e glossário por G. Rockhill, trad. V. Brito. Porto: Dafne, 2010.

. O Espectador Emancipado. São Paulo: Martins Fontes, 2012 (a).

. O destino das imagens. Rio de Janeiro: Contraponto, 2012 (b).

SANTOS, Milton. A Natureza do Espaço: Técnica e Tempo, Razão e Emoção / Milton Santos. - 4. ed. 2. reimpr. - São Paulo: Editora da Universidade de São Paulo, 2006. (Coleção Milton Santos; 1)

. Metamorfoses do espaço habitado - fundamentos teórico e metodológico da geografia. São Paulo: Hucitec, 1988.

SMOLKA, Ana Luiza Bustamante. A memória em questão: uma perspectiva históricocultural. In: Educação e Sociedade, ano XXI, nº 71, jun/ 2000.

Doutorando em Artes Visuais pela Escola de Comunicação e Artes da Universidade de São Paulo (ECA-USP). Mestre em Artes Visuais pela Escola de Comunicação e Artes da Universidade de São Paulo (ECA-USP). Pós-graduado em Musica no Século XX Computação Sônica pela Universidade Federal de Uberlândia (UFU) MG. Fez Pósgraduação em Arte e Cultura no Século XVIII Barroco Mineiro na Universidade Federal de Ouro Preto MG. Graduado em Educação Artística Habilitação em Artes Plásticas pela Universidade Federal de Uberlândia (UFU) MG. 